\title{
A assistência às crianças na viagem para o além, na Braga setecentista
}

\section{The assistance to the children on the voyage to the afterlife in the Braga of the XVIII century}

\author{
Norberto Tiago Gonçalves Ferraz*
}

\begin{abstract}
Resumo
O objetivo deste artigo é fornecer novos dados historiográficos sobre a assistência concedida às crianças da cidade de Braga, na ocasião do seu falecimento, no século XVIII. No trabalho que realizamos, foi possível analisar alguns dados sobre o anúncio da morte das crianças de Braga, os seus velórios, sepultamentos e a assistência às suas almas, através de fontes documentais das confrarias da cidade e das Constituições Sinodais do arcebispado. A análise testamental forneceu menos dados, mas revelou a provável preocupação de alguns indivíduos, com a salvação das almas dos filhos falecidos com mais de sete anos de idade.
\end{abstract}

Palavras-chave: Braga; morte; crianças; assistência.

\begin{abstract}
The purpose of this article is to give new historical data about de assistance given to de children of the city of Braga, on the occasion of their deaths, in the XVIII century. In the work that we done it was possible to analyse some data about the announcement of death of the children of Braga, their funerals, graves and the assistance to their souls, through the documental sources of the confraternities of the city and the Constitutions of the archbishopric. The testamental analysis gave less data, but revealed the probable preoccupation of some individuals with the salvation of the souls of their sons, that died with more than seven years of age.
\end{abstract}

Keywords: Braga; death, children; assistance. 


\section{Introdução}

A morte é condição natural do ser humano e as diferentes civilizações, ao longo dos milénios, procuraram enquadrar a nível religioso e social, essa última etapa da vivência do homem. Diversas práticas rituais eram executadas, tendo em vista a passagem segura do defunto para o mundo do além. O cristianismo, que a partir do século IV da nossa era, se tornou a religião oficial do mundo ocidental europeu, ${ }^{1}$ não deixou, deste modo, de procurar orientar as consciências e mentalidades dos povos que habitavam neste espaço geográfico, ao longo dos séculos seguintes, no que dizia respeito a esta questão.

Ora, no contexto religioso católico da Idade Moderna, era fulcral, durante a vida terrena, preparar a alma para o dia do encontro final com Deus, de modo a garantir a sua salvação, evitando a condenação eterna e procurando diminuir ao máximo o tempo de permanência da alma no Purgatório. Este surgiu somente durante a Idade Média, no século XII, como um local de expiação das almas que não tinham ainda adquirido a perfeição de modo a poderem entrar no Paraíso. ${ }^{2}$ Contudo, este novo "lugar" não adquiriu, de imediato, um estatuto de igualdade em relação ao Paraíso e ao Inferno, dentro da mentalidade medieval. Foi somente no século XVI, com as críticas protestantes que negavam a sua existência, que a Igreja Católica sentiu necessidade de reforçar, a partir do Concílio de Trento, a presença do Purgatório nas crenças das populações. ${ }^{3}$ Através da pregação da Igreja, os homens e mulheres eram instruídos sobre este local em que a alma, ainda que sofrendo o castigo das suas faltas, podia ambicionar à salvação. A Igreja exortou, deste modo, os indivíduos a investir os seus recursos na salvação da alma, levando os fiéis a mandarem celebrar missas, perpétuas ou não, no sentido de libertá-la rapidamente das penas purgatoriais.

\footnotetext{
${ }^{1}$ Como é sabido, será a partir dos séculos XV-XVI que, com o período das descobertas, o cristianismo será introduzido noutras regiões do mundo, como as Américas.

${ }^{2}$ Sobre o surgimento do Purgatório no século XII leia-se Vovelle (1996, p. 19, 41-42, 48).

${ }^{3}$ Consulte-se Vovelle (1996, p. 93).
} 
É neste contexto religioso sobre a morte e a salvação da alma, que estava inserida a cidade de Braga na centúria setecentista, palco de um estudo mais abrangente que efetuamos sobre esta temática. A cidade de Braga tinha, no início do século XVIII, cinco freguesias: São Vítor ${ }^{4}$, Sé, São João do Souto, Maximinos e Cividade. Por ordem do arcebispo D. José de Bragança (1741-1756), a freguesia de São Vítor foi dividida em duas e criada a paróquia de São José de São Lázaro, em 1747 (SENNA DE FREITAS, 189ob, p. 460). O centro religioso da cidade era a Sé Primaz, mas cada freguesia tinha a sua igreja paroquial correspondente. 5 Todavia, os edifícios de culto da cidade estavam longe de se resumir a estas igrejas: existiam outras capelas e igrejas não paroquiais, algumas pertencentes a confrarias, ou que se englobavam nos diversos conventos e mosteiros citadinos, também eles locais de culto que apelavam à devoção religiosa popular bracarense. 6 No mesmo sentido se deve assinalar também a existência de uma Ordem Terceira de São Francisco, bem como da Santa Casa da Misericórdia local.

Em Braga, o arcebispo era a autoridade suprema, já que detinha o senhorio temporal da cidade que governou até 1790, data em que este foi extinto pelo Estado, ficando apenas com o governo religioso.7 Existia uma Câmara Municipal que o arcebispo tutelou até essa data. Na verdade até 1710, o arcebispo de Braga, já de si a cabeça de uma grande arquidiocese, fora a autoridade máxima a nível religioso nacional, data em que foi criado o patriarcado de Lisboa. Na hierarquia religiosa da cidade o cabido dos cónegos era outro órgão importante, o qual, por vezes, entrava em conflito com o arcebispo, pois detinha igualmente o poder de administração de bens imóveis que lhe pertenciam e auferia bastantes rendas e riquezas. ${ }^{8} \mathrm{O}$ corpo eclesiástico local era bastante numeroso, sendo constituído sobretudo por clérigos denominados reverendos ou padres, embora também existissem outros ligados à administração eclesiástica, bem como beneficiados. 9 A

\footnotetext{
${ }^{4}$ A freguesia de São Vítor incluía na Idade Moderna uma zona urbana e uma zona do termo. Confira-se Costa (1979, p. 19).

${ }^{5}$ A importância da arquidiocese de Braga mostrava-se igualmente pelo facto de esta ter um rito litúrgico próprio, o rito bracarense, em detrimento do ritual romano. Leia-se Marques (2000, p. 430).

${ }^{6}$ Sobre os conventos e mosteiros de Braga consulte-se Senna de Freitas (1890a, p. 205-216); Silva (2011, p. 71-95); Soares (2009, p. 244-245).

${ }^{7}$ Sobre o senhorio temporal e religioso dos arcebispos confira-se Abreu (1997, p. 57-59); Alvarenga (1742, p. 33-34).

${ }^{8}$ Confira-se Soares (1997, p. 45, 58). Arcebispos como D. Rodrigo de Moura Teles ou D. José de Bragança tiveram vários conflitos com o cabido. Consulte-se Abreu (1997, p. 71).

${ }^{9}$ A propósito do corpo eclesiástico bracarense confira-se Capela; Ferreira (2002, p. 170, 171).
} 
par do clero secular existiam igualmente diversas comunidades monásticas. Eram mais de 500 os ingressos nos conventos femininos e masculinos da cidade. Ao clero sacerdotal cabia a celebração de milhares de missas nos diversos templos e altares citadinos, todos os anos. ${ }^{10}$

A cidade, a nível de manifestações do culto religioso, tinha as suas procissões que atraíam o povo à rua, como a do Ecce Homo realizada pela Santa Casa da Misericórdia local ${ }^{11}$, a do enterro do Senhor promovida pela irmandade de Santa Cruz ou a do Corpo de Deus, e também diversas festas em honras de santos. Por seu turno, a Ordem Terceira promovia a procissão de Cinzas no primeiro dia da Quaresma. ${ }^{12}$

Em termos económicos é importante referir que a cidade e os seus arredores produziam muitos produtos hortículas e frutícolas.13 A produção pecuária era também assinalável, proveniente não só das suas zonas rurais, como também das regiões envolventes. ${ }^{14}$ Já os ofícios artesanais do setor secundário ocupavam um lugar significativo no tecido económico bracarense setecentista. Os de maior importância eram os sombreiros, os sapateiros, os alfaiates, os ourives e os carpinteiros, os torneiros e os serralheiros. Por seu turno, o setor terciário era sobretudo composto por vendeiros e os funcionários da administração civil, religiosa e militar. Já no setor primário agrícola trabalhavam, essencialmente, lavradores e jornaleiros.

O cenário socioeconômico bracarense conheceu épocas de crise. Entre 1768 e 1770, tiveram lugar tempestades naturais, seguidas de epidemias que debilitaram a população. Posteriormente, a década de 1790 foi também profícua em epidemias, fomes e maus anos agrícolas, com a correspondente alta de preços nos bens essenciais. ${ }^{15}$

\footnotetext{
${ }^{10}$ Para o número de comunidades conventuais bracarenses na Idade Moderna, leia-se Silva (2011, p. 121-123, 130).

11 As primeiras Misericórdias foram fundadas no final do século XV em Portugal, sob os auspícios da rainha D. Leonor. Era obetivo destas instituições praticar as 14 obras de Misericórdia definidas pela Igreja Católica. Destacaram-se sobretudo na assistência hospitalar. A nível cultual celebravam as cerimónias da Semana Santa. A Misericórdia de Braga foi fundada em 1513.

${ }^{12}$ Confira-se, para este assunto, Moraes (2009, p. 265-268); Senna de Freitas (1890c, p. 319, 431).

${ }^{13}$ Em relação aos bens produzidos confira-se Senna de Freitas (1890c, p. 407-411).

${ }^{14}$ Leia-se Capela $(1999$, p. 60, 63).

${ }^{15}$ Sobre as épocas de crise económica e financeira, bem como de epidemias na cidade de Braga, leia-se Barbosa (2001, p. 24-26).
} 


\section{A assistência às crianças bracarenses na "última" viagem}

É este o contexto do estudo a que procedemos sobre a vivência da morte e a salvação da alma na Braga setecentista. Nele pudemos avaliar diversas vertentes na forma como os bracarenses lidavam e preparavam a sua viagem para o além. Como foi efectuado este trabalho? Através do estudo das Constituições Sinodais da Arquidiocese de Braga, publicadas em 1538 e 1697, da análise de 250 testamentos bracarenses do século XVIII, e de diversos fundos arquivísticos e documentais das confrarias desta cidade, referentes à mesma centúria, ficou patente a preocupação que os citadinos manifestavam no cuidado a ter com os seus restos mortais, na escolha da mortalha, quer na designação da sua última morada.

Ficou igualmente manifesto o seu anseio na procura da salvação da alma das penas do Purgatório mediante a celebração de sufrágios e ofícios. Na execução das diferentes dimensões que abarcavam todo o processo da passagem para o outro mundo e da busca da salvação, as confrarias locais tiveram um papel fundamental. Mas dentro desta temática abrangente, será possível identificar especificidades no que às crianças bracarenses dizia respeito? Como era vista a sua relação com o além? Que assistência era prestada às suas almas e corpos?

Um primeiro ponto de partida nesta análise refere-se a uma verdade teológica do catolicismo, relativamente à salvação dos indivíduos desta faixa etária. Os menores que tivessem até sete anos de idade eram por isso considerados incapazes de pecar. Assim, desde que fossem batizados, tinham a salvação garantida, no caso de falecerem. ${ }^{16}$ Era um fator de consolo para os seus pais, especialmente se nos lembramos que estávamos numa época de elevada mortalidade infantil.

A morte do indivíduo era anunciada aos habitantes de Braga pelo ressoar sineiro. As Constituições Sinodais Bracarenses de 1697 previam, para este anúncio, um único sinal para os menores entre os sete e os catorze anos, acrescido de outros

\footnotetext{
${ }^{16}$ Sobre a certeza da salvação para os menores de sete anos de idade, confira-se Amorim (1987, p. 275).
} 
três no momento do enterro. Portanto, o assinalar da morte destas crianças regiase já por uma regra própria. Não sabemos, todavia, o que estaria determinado no caso de crianças com menos de sete anos de idade, pois este documento era omisso nesse respeito.

A pesquisa documental confraternal mostrou que certas irmandades previam toques específicos para assinalar a morte dos seus membros. Encontrámos igualmente certas particularidades definidas por estas confrarias relativamente aos menores. Na década de 1780 sabemos que a irmandade de Nossa Senhora a Branca determinou um desconto no custo do toque de sinos para anúncio da morte dos filhos menores dos seus confrades. Por seu turno, na mesma década, a irmandade de Santa Cruz concedeu também, total liberdade para ressoarem os sinos quando fossem enterradas crianças na sua igreja, sem determinar número prévio. Todos estes indicadores parecem demonstrar uma crescente atenção relativa ao anúncio sonoro do falecimento das crianças na centúria setecentista bracarense.

Os acompanhamentos fúnebres eram outra das etapas fundamentais na vivência da morte na Idade Moderna. As confrarias bracarenses constituíram-se como actores fundamentais no acompanhamento dos defuntos à sepultura. Sabemos que sepultavam os seus membros a título gratuito e acompanhavam elementos externos mediante pagamento. Teriam, todavia, uma prática dirigida especificamente às crianças? O que pudemos constatar é que estas instituições dispunham-se a acompanhar os familiares dos confrades, que vivessem debaixo da sua tutela, mediante um preço menor em comparação com aquele praticado relativamente a outros indivíduos exteriores às irmandades. Deste modo, os acompanhamentos fúnebres das crianças filhas dos confrades dispunham de um desconto considerável, rondando geralmente metade do preço.

Os montantes a pagar estavam estabelecidos nas regras estatutárias e representavam valores distintos. Por exemplo, a irmandade de São Vicente definiu, em 1723, para o acompanhamento fúnebre dos não irmãos, o pagamento de 1500 
réis. Para os mencionados familiares do confrade, o preço era de apenas 720 réis. ${ }^{17}$ Por seu turno, a irmandade de São Crispim, sedeada na igreja da Sé, definiu no início do século XVIII que o montante a pagar pelos acompanhamentos era de 1000 réis em geral, e de 500 réis para os familiares que estivessem dentro das condições já apresentadas, valores que em 1731 foram aumentados para 1200 e 600 réis respetivamente. ${ }^{18}$

Por seu turno, os acompanhamentos facultados pela irmandade de Nossa Senhora do Ó tinham valores variados, no início do século XVIII. A confraria estabeleceu, estatutariamente, um valor base de 1000 réis para os acompanhamentos dos defuntos não confrades. Simultaneamente, a instituição concedia a regalia aos filhos dos confrades e outros parentes que com eles vivessem, de terem um acompanhamento pelo preço de 500 réis, valor que aumentava para 800 se estes não vivessem sustentados pelos confrades. Os dados compulsados nas fontes demonstram que, a partir da década de 1720 até ao início da de 1770, os preços estabilizaram: os dos não confrades tinham o custo de 1200 réis e os dos familiares de confrades por estes tutelados, metade desse preço. ${ }^{19}$

Já a irmandade de Santa Cruz, que no início do século requeria um pagamento de 3000 réis para os acompanhamentos aos não confrades em geral e de 1500 réis para o acompanhamento a familiares de irmãos, fez uma atualização significativa em 1773, passando os não irmãos a pagar 9600 réis. Esta quantia foi posteriormente revista em 1788, baixando para 8000, enquanto nesse ano os familiares de irmãos passaram a pagar 2400 réis, em vez dos 1500 até então praticados. ${ }^{20}$ Portanto, o que constatamos neste particular é que as crianças filhas

\footnotetext{
${ }^{17}$ Arquivo da Igreja de São Vicente, doravante AISVTE, Fundo da irmandade de São Vicente, Livro de estatutos reformados da irmandade de São Vicente, 1723, fls. 27-28; Livro de estatutos reformados da irmandade de São Vicente 1768, fl. 54v.; Livro de termos de junta da irmandade de São Vicente, 1796-1806, fl. 45.

${ }^{18}$ Arquivo da Igreja da Sé de Braga, doravante AISB, Fundo da irmandade de São Crispim e São Crispiniano, Livro de estatutos da irmandade de São Crispim e São Crispiniano, 1702, fl. 16; Livro de estatutos da irmandade de São Crispim e São Crispiniano, 1731, fls. 31v.-32; Livro da receita da irmandade de São Crispim e São Crispiniano, 1748-1789, fls. 92-95v.; Livro dos termos da irmandade de São Crispim e São Crispiniano, 1790-1874, fl. 49v.

${ }^{19}$ Arquivo da Igreja de Nossa Senhora a Branca doravante AINSB, Fundo da irmandade de Nossa Senhora do Ó do Hospital de São Marcos, Estatutos da irmandade de Nossa Senhora do Ó, 1701, fls. 16-17; Livro do recibo da irmandade de Nossa Senhora do Ó, 16761724, fls. 119-123, 139-143v., 175v.-178, 193v.-196, 216v.-220; Livro do recibo da irmandade de Nossa Senhora do Ó, 1724-1771, fls. 1-6v., 29-33v., 52v.-56v, 81v.-86, 102-105, 119-122, 136-138, 152-153v.,

${ }^{20}$ Arquivo da Igreja de Santa Cruz doravante AISC, Fundo da irmandade de Santa Cruz, Livro de estatutos da irmandade de Santa Cruz, 1664, 1702, 1762, 1773, fls. 277v., 384; 485; Livro de estatutos da irmandade de Santa Cruz, Bom Jesus dos Santos Passos e Santa Ana, 1788 , fl. 77.
} 
dos membros das confrarias bracarenses acabavam por ser enquadradas nestes descontos, em comparação com outros indivíduos estranhos às confrarias, ainda que estes benefícios não fossem dirigidos especificamente apenas para elas, mas antes a todos os parentes dos confrades que com eles vivessem.

Relativamente ao acompanhamento deste grupo etário à sepultura devemos assinalar que a Misericórdia bracarense ocupava-se do enterro das muitas crianças que apareciam mortas nas ruas da cidade de Braga, na Idade Moderna, para além de se comprometer a sepultar gratuitamente todos os pobres, incluindo, portanto, as crianças que nesta situação se encontrassem. Esta acção caritativa da Santa Casa era complementada pela irmandade das Almas de São Vítor, que acompanhava à sepultura os pobres desta freguesia, neles se incluindo as crianças, residentes nas zonas mais distantes, para lá dos limites da cidade e que por isso ficavam fora do alcance assistencial da Misericórdia. ${ }^{21}$

Devemos igualmente salientar que, em relação ao transporte das crianças defuntas, as fontes documentais da grande maioria das confrarias por nós estudadas não registam a existência de um esquife ou de um caixão específico para o enterro dos menores. Sabemos, contudo, que a Congregação do Senhor das Necessidades de São Vítor, em 1780, tinha em sua posse caixões para o enterro de crianças. Do mesmo modo, também a irmandade das Almas de São Vítor, em 1753, decidira adquirir um caixão pequeno destinado ao transporte das crianças defuntas. Estes aspectos demonstram que, desde meados desta centúria, já existia em algumas instituições a noção da pertinência sobre a utilização de um objecto de transporte fúnebre, que fosse associado e adequado a esta faixa etária. ${ }^{22}$ Não é de excluir que outras instituições congéneres também os possuíssem, mas que a falta de registo documental não os assinale.

\footnotetext{
${ }^{21}$ Arquivo da Igreja de São Vítor, doravante AISV, Fundo da Confraria das Almas de São Vítor, Livro de estatutos da confraria das Almas de São Vitor, 1738, fl. 19v.; Livro de termos de mesa da irmandade das Almas de São Vitor, 1776-1794, fl. 241v.; Livro dos peditórios dos mordomos da irmandade das Almas de São Vítor, 1738-1754, fls. 19-21, 24v., 33-33v., 37v.-38, 44v.-45, 50v.-52, 54-55, 61v.-62, 67-67v., 72-72v., 77v.-78, 83-83v., 88v.-90v., 93v.-96.

${ }_{22}$ AISV, Fundo da Congregação do Senhor das Necessidades, Apontamentos por onde se rege esta congregação do Senhor das Necessidades, 1758-1780, não paginado. AISV, Livro de termos de mesa da confraria das Almas de São Vítor, 1752-1776, fl. 21v.
} 
Um outro aspeto que podemos analisar refere-se ao depósito dos defuntos para o velório. A análise testamental a que procedemos demonstrou que, desde meados do século XVIII, se foi progressivamente consolidando em Braga a prática de transportar de imediato os defuntos para as igrejas no sentido de aí serem velados até ao sepultamento. Ou seja, transferia-se o período de velório dos mortos, das habitações domésticas para os espaços religiosos. Encontraremos aqui especificidades relativamente ao grupo etário infantil?

$\mathrm{Na}$ verdade, a irmandade de São Vicente começou a cobrar 60 réis pelo depósito de crianças, possivelmente até aos sete anos de idade ${ }^{23}$ e o dobro do preço pela exposição dos corpos das restantes pessoas. Na década de 1770, o depósito de crianças foi pago a 120 réis, valor que seria certamente o dobro para os adultos. As regras redigidas em 1783 determinaram que o custo do depósito dos cadáveres dos indivíduos estranhos à instituição, na igreja de São Vicente, implicava uma despesa de 300 réis. Em relação às crianças pequenas, o depósito do seu corpo tinha um custo de 150 réis. ${ }^{24} \mathrm{~A}$ irmandade não diferenciava entre as crianças filhas de confrades e aquelas que o não eram.

Por seu turno a irmandade da Senhora-a-Branca em 1768/1773 determinou que o custo da exposição do cadáver para qualquer pessoa exterior à instituição era de 240 réis, não distinguindo entre crianças e adultos. Todavia, ao contrário da irmandade de São Vicente, a irmandade cobrava apenas 120 réis sobre os depósitos dos defuntos filhos de confrades, que tivessem até 16 anos de idade. Ou seja, esta irmandade, definia claramente uma idade máxima para atribuir este desconto à deposição dos defuntos filhos de confrades. Se na confraria de São Vicente a diferença se estabelecia entre crianças e adultos em geral, na de Nossa Senhora-aBranca o critério diferenciador era o de tratarem-se ou não de filhos de membros da instituição. Em 1788 os depósitos dos cadáveres dos indivíduos não confrades foram fixados em 300 réis, não se discriminando entre adultos e crianças. Todavia,

\footnotetext{
${ }^{23}$ Efetivamente, as fontes documentais não indicam uma idade precisa dos menores.

${ }^{24}$ A atualização efetuada em 1783, não impediu a instituição de proceder com alguma liberdade, tendo em atenção certos casos específicos, como no enterro de uma criança que era filha de um confrade e irmã do servente mais novo da irmandade. Tendo em atenção estes dois aspetos, os mesários aceitaram o seu enterro gratuito. AISVTE, Fundo da irmandade de São Vicente, Livro de termos de mesa da irmandade de São Vicente, 1781-1790, fls. 80-80v.; Livro de termos de mesa da irmandade de São Vicente, 1796-1803, fl. 32v.
} 
os filhos dos confrades que estivessem sob o poder pátrio continuaram a ser contemplados com um desconto de 50\% na exposição do seu corpo na igreja.

Relativamente ainda ao velório dos defuntos há ainda outro aspeto a relevar. A partir de finais da década de 1760, surgiram referências a alugueres de capelas de flores, ou seja uma ornamentação floral que adornava a cabeça dos defuntos, bem como de palmitos para a exposição dos mortos, na contabilidade da irmandade de Santa Cruz e, especialmente, na de Nossa Senhora-a-Branca. Os palmitos eram um ramo, ou palma pequena, que era colocada nas mãos das crianças e das donzelas, aquando do seu velório. ${ }^{25}$ Sabemos que tanto as capelas como os palmitos parecem ter sido utilizados sobretudo nos funerais de crianças, ocorridos nestas igrejas. ${ }^{26}$ Assim, através da ligação destes dados, verificamos que algumas confrarias tinham na sua posse certos objetos simbólicos para compor e embelezar as crianças defuntas, nos seus velórios, desde que tal fosse requerido pelos pais.

Esta preocupação com determinados gestos de respeito, dedicação e até carinho perante os seus filhos defuntos, significaria o crescimento de uma nova atitude, perante a mortalidade infantil, por parte dos pais bracarenses no fim do século XVIII? Na Idade Moderna, a mortalidade infantil, pela sua grande ocorrência, era tida como natural, de tal forma que, segundo alguns autores, os pais tendiam a não criar fortes laços sentimentais com os seus filhos, enquanto estes fossem de tenra idade. ${ }^{27}$ Serão estes sinais que encontrámos, reveladores de uma mentalidade em mudança? Poderão ser também, de qualquer modo, um reflexo da crença na salvação imediata da alma dos que tinham tido uma existência breve sobre a terra. ${ }^{28}$ Com as elevadas taxas de mortalidade infantil existentes, os mesários destas confrarias poderão ter constatado as vantagens de disponibilizar

\footnotetext{
${ }^{25}$ Relativamente às prováveis definições dos volantes, capelas e palmitos, confira-se Bluteau (Tomo I, 1712, p. 122; Tomo VI, p. 207, 210; Tomo VIII, p. 554-555); Costa, 1994, p. 338, 1239, 1876).

${ }^{26}$ AISNB, Fundo da irmandade de Nossa Senhora-a-Branca, Livro do recibo da irmandade de Nossa Senhora-a-Branca, 1669-1738, fls. 182v.-185; Livro do recibo dos emolumentos e esmolas das covagens, pano da sepultura, depósitos, limpeza dos ornatos das missas gerais, sinais, repiques e esmolas, 1754-1779, fls. 5-9v., 24v.-29v., 43v.-.45, 62-65v., 81v.-85; Livro dos emolumentos ou esmolas que se deram pelas covagens, pano de sepultura, depósitos e limpeza dos ornatos das missas gerais, sinais, repiques e esmolas, 1779-1826, fls. 3-6v., 22-24v., 37-40, 52v.-55v., 64v.-67.

${ }^{27}$ Para este assunto, leia-se Sá $(2011$, p. 73). Sobre a elevada mortalidade infantil e a relação dos pais com os seus filhos menores defuntos em terra idade, consulte-se igualmente Garnot (1995, p. 57, 60, 75).

${ }^{28}$ Até aos sete anos de idade as crianças deviam já ter recebido os sacramentos do baptismo e da confirmação. A partir dessa idade deviam começar a confessar-se. Confira-se Constituições Synodais do Arcebispado de Braga (1697, p. 7-8, 26, 29, 33).
} 
meios que possibilitassem aos adultos a manifestação do seu sentimento pela morte dos filhos. Estas informações sobre os enterros das crianças são, no nosso entender, pertinentes, pois não são muitos os estudos sobre este assunto em Portugal.

Uma outra dimensão a considerar relaciona-se com os locais de sepultamento. As confrarias de São Vicente, do Bom Jesus dos Santos Passos, de Santa Cruz e a de Nossa Senhora-a-Branca eram detentoras de edifícios religiosos que acolheram os corpos de muitos citadinos, confrades ou não. Ora o que pudemos constatar foi que também neste particular as confrarias previam certos benefícios aos parentes dos confrades em geral, nele se incluindo as crianças que com eles viviam.

A irmandade do Bom Jesus dos Santos Passos estava sedeada desde 1723 na igreja de Santa Ana. Os estatutos de 1747 vieram definir as regras de funcionamento da concessão de sepulturas por parte da confraria, quer no que dizia respeito às que possuía igualmente no convento do Pópulo, quer em relação às da igreja de Santa Ana. Relativamente aos enterros no transepto desta igreja, os estatutos previam que os confrades pudessem sepultar aí os seus filhos, pais e irmãos que vivessem em sua casa, sob seu sustento, pagando 2400 réis para a instituição e 400 para o servo ${ }^{29}$ abrir a cova, metade do preço previsto para as restantes pessoas estranhas à confraria.

No que dizia respeito ao sepultamento dos filhos dos confrades na nave da igreja se tivessem mais de sete anos de idade o pagamento cifrava-se em apenas 240 réis, a que deviam acrescentar mais 200 para o servo. Já as restantes pessoas que não pertencessem à irmandade eram sepultadas nessa zona do templo mediante o dispêndio de 480 réis para a instituição. Relativamente a este espaço específico de inumação dos corpos, dentro da igreja de Santa Ana, é importante igualmente referir que a irmandade concedia uma atenção específica às crianças que tivessem até sete anos de idade. As que fossem filhas dos confrades podiam ser

\footnotetext{
${ }^{29}$ Sobre os servos, veja-se mais adiante a descrição das suas funções.
} 
aí sepultadas, pelo pagamento de apenas 100 réis à irmandade e 120 réis ao coveiro, ao passo que as que não estavam nessa condição podiam ter direito a sepultura mediante o pagamento de 200 réis para a instituição, acrescidos de 150 réis para o servo.30

Portanto, em qualquer dos casos, o sepultamento de indivíduos até aos sete anos de idade na nave da igreja beneficiava de um desconto, que variava mediante o facto de serem ou não filhos de confrades. Todavia, os enterros de crianças com mais de sete anos só motivavam uma diminuição do preço se estas fossem filhas de membros da instituição.

Esta irmandade manteve a posse de algumas sepulturas no convento do Pópulo, após uma longa querela judicial com os frades agostinhos. A instituição determinou que os filhos dos confrades podiam ser aí sepultados mediante pagamento ao coveiro e desde que seus pais fornecessem cal e vinagre para deitar sobre os corpos, a exemplo de todos os irmãos. $3^{1}$

Por seu turno, os estatutos de 1723 da irmandade de São Vicente nada previam em relação aos preços a aplicar aos enterros das crianças. Todavia a consulta de outras fontes documentais demonstrou que os mesários cobravam 100 réis pelo seu enterro, ou seja, metade do preço cobrado por um adulto e não praticavam qualquer diferenciação entre os filhos de confrades e aqueles que não o eram.

Posteriormente em 1783 a irmandade determinou que o enterro de crianças pequenas, possivelmente até aos sete anos de idade, era efetuado mediante o pagamento de 320 réis para a confraria e 160 réis para o servente, quando o enterro de adultos se fixou em 700 réis para a irmandade e 200 para o coveiro. Esta

\footnotetext{
${ }^{30}$ Durante a maior parte da Idade Moderna, a mortalidade infantil abaixo dos sete anos de idade raramente era registada nos registos paroquiais, sendo por isso desvalorizada. Leia-se Santos (1999, p. 193). Aparentemente, em meados do século XVIII, algumas confrarias, como a do Bom Jesus dos Santos Passos estavam a conceder maior atenção a esta faixa etária, ao nível dos sepultamentos.

${ }^{31}$ AISC, Fundo da irmandade do Bom Jesus dos Santos Passos, Livro de estatutos da irmandade do Bom Jesus dos Santos Passos, 1747, fls. 131v.-133, 135; Livro dos rendimentos da casa e anais, 1628-1708 e de 1737 até se incorporar na irmandade de Santa Cruz em 1772, da irmandade dos Santos Passos e Santa Ana, fls. 373v.-378, 427, 430, 488v.-489, 512v., 521-521v., 532, 542-552v., 554, 562, 566v.-569; Livro de termos de mesa da irmandade do Bom Jesus dos Passos, 1740-1772, fls. 609v.-610.
} 
atualização das regras de sepultamento na nave da igreja definiu ainda condições mais favoráveis para os enterros dos filhos dos confrades, ou de qualquer outra pessoa que vivesse em casa destes à sua custa. Os enterros destes indivíduos custariam metade do preço a despender com os enterros de outros indivíduos que fossem estranhos à instituição. A título de exemplo o enterro de uma criança filha de um confrade custaria metade do preço do enterro de uma criança que o não fosse.

A confraria de Nossa Senhora-a-Branca definiu, nos estatutos de 1724, que o enterro de crianças até aos sete anos era efetuado por metade do preço das restantes pessoas. ${ }^{2}$ Estes montantes referiam-se aos enterros das pessoas estranhas à irmandade. Os estatutos seguintes de 1768, procedendo a actualizações mantiveram, grosso modo, este diferencial, com ligeiros ajustamentos.33 Contudo, já perto do fim do século, as regras estatutárias de 1788 definiram igualmente que o enterro de qualquer filho dos irmãos da confraria, debaixo da sua tutela, em qualquer área da igreja, custava somente metade do preço do que pagavam os não confrades, pesando também no custo final o facto de estes filhos terem ou não até sete anos, a exemplo do que sucedia na irmandade de São Vicente. 34

A irmandade de Santa Cruz estabeleceu nos estatutos de 1702 que os enterros dos defuntos não confrades, crianças ou adultos, tinham o mesmo custo, que era de 1000 réis à irmandade e 400 ao coveiro. Já os enterros dos filhos dos irmãos, de menor idade, implicavam uma despesa de 500 réis pagos à instituição e 200 ao coveiro. Alguns anos depois, em 1720, uma reforma estatutária veio modificar uma norma. A irmandade passou a conceder sepultura gratuita aos filhos dos confrades, até aos 25 anos de idade, que estivessem debaixo da tutela parental, tendo somente de pagar ao coveiro. 35

\footnotetext{
32 Os dados que obtivemos em relação ao período anterior a 1723 indicam que os preços definidos nestes estatutos seriam já os que vinham a ser praticados desde o início do século XVIII. AINSB, Fundo da irmandade de Nossa Senhora-a-Branca, Livro do recibo da irmandade de Nossa Senhora-a-Branca, 1669-1738, fls. 123-126.

${ }_{33}$ AINSB, Fundo da irmandade de Nossa Senhora-a-Branca, Estatutos da irmandade de Nossa Senhora das Neves sita na capela da Senhora-a-Branca, 1768/1773, fls. 37-39.

${ }^{34}$ AINSB, Fundo da irmandade de Nossa Senhora-a-Branca, Estatutos da confraria da Senhora das Neves, 1788, fls. $22-23$.

${ }^{35} \mathrm{Em} 1731$ a Misericórdia de Fão concedeu às mulheres e aos filhos dos confrades as mesmas condições de enterro que proporcionava aos seus membros. Veja-se, sobre estas regalias, Mariz (2000, p. 62).
} 
Os estatutos de 1773 mantiveram o preço de mil réis, em geral, para o sepultamento de adultos estranhos à confraria na sua igreja, mas determinou que as crianças sem parentesco com os irmãos da instituição eram agora enterradas mediante o pagamento à instituição de 500 réis. Foi, portanto, apenas numa época bem mais tardia da centúria setecentista, em comparação com as congéneres dos Santos Passos, São Vicente e Nossa-Senhora-a-Branca, que a irmandade de Santa Cruz diferenciou o preçário entre crianças e adultos que não pertenciam à confraria. 36

Por fim, as regras redigidas em 1788 procederam a uma atualização em alta dos preços dos enterros dos não confrades, mas mantendo o diferencial entre adultos e crianças. 37 Teve também lugar outra mudança: definiu-se que a idade até à qual os menores podiam beneficiar desta diminuição de preço, era a de 10 anos. Ou seja, a irmandade estabeleceu um intervalo etário mais alargado do que outras congéneres, que só concediam esse preçário até à idade de sete anos.

Salientemos ainda que os preços para os sepultamentos praticados pelas confrarias de São Vicente e de Nossa Senhora-a-Branca podem ajudar a explicar a grande procura das suas igrejas, em comparação com a de Santa Cruz, por parte dos progenitores com menores posses que desejavam encontrar um local de sepultamento que lhes parecesse digno para os seus filhos.

Existe ainda um outro ponto que, pensamos, merece a nossa atenção. Certas irmandades por nós estudadas estabeleceram a existência de um servidor nas suas igrejas para cuidar da limpeza e asseio das mesmas, abrir as suas portas, velar pelas alfaias e paramentos litúrgicos ou ainda fazer ressoar os sinos. Estes indivíduos, designados como "servos”, eram homens adultos que preparavam os altares para as celebrações e ajudavam os clérigos, além de, por vezes, percorrerem as ruas para chamarem os irmãos aos acompanhamentos de defuntos e procederem aos enterramentos dos mesmos. Ora, a nossa investigação revelou que as confrarias de

\footnotetext{
${ }^{36}$ AISC, Fundo da irmandade de Santa Cruz, Livro de estatutos da irmandade de Santa Cruz, 1663, 1702, 1762, 1773, fls. 384v.-385v., 485-486v.

${ }^{37}$ Estas alterações tinham sido já introduzidas numa reunião da Mesa em 1782. AISC, Fundo da irmandade de Santa Cruz, Livro de termos de mesa e juntas da irmandade de Santa Cruz, 1772-1790, fl. 387v.-388.
} 
São Vicente, Santa Cruz e Nossa Senhora-a-Branca, contrataram também jovens moços a partir de 10/12 anos para ajudarem aos serventes mais velhos nestas tarefas. 38

Pela execução das suas tarefas, estes serventes de menor idade recebiam um salário. A irmandade de Nossa Senhora-a-Branca introduziu um rapaz ao serviço da instituição, no ano de 1788. A instituição definiu como salário anual do "servo menor" 2400 réis, dois pares de meias, um chapéu, uma volta para o cabeção e dois pares de sapatos. Para além deste valor monetário, de três em três anos, recebia uma veste, com capa e loba de "pano azulado." Finalmente tinha direito a receber 100 réis de cada irmão que ingressasse na irmandade.39

Analisemos, do mesmo modo, a evolução salarial dos serviçais da irmandade de Santa Cruz. Segundo os estatutos de 1702, os servos mais novos auferiam, cada ano, dois pares de sapatos, igual número de solas e um par de meias. De dois em dois anos, concediam-lhe roupas que consistiam numa capa, um gibão, um calção e um chapéu. Chamamos a atenção para o facto de os servos mais novos receberem roupa e sapatos nas mesmas condições do servo adulto. Eram igualmente pagos em géneros, o que se traduzia em 25 alqueires de pão. Monetariamente, recebiam também a quantia de dois mil réis anuais. 40

Em 1762, com a remodelação do quadro dos serventes, teve lugar uma atualização dos salários. O servo mais jovem da irmandade de Santa Cruz passou a receber de salário, todos os anos, 4800 réis, para além de dois pares de sapatos e de meias, mantendo os 25 alqueires anuais de pão meado. A nível do vestuário a irmandade fornecia-lhe, de dois em dois anos, uma capa, uma loba de pano roxo, uma veste, uns calções e um chapéu.

\footnotetext{
${ }^{38}$ AISC, Fundo da irmandade de Santa Cruz, Livro de estatutos da irmandade de Santa Cruz, 1702, 1762, 1773, fls. 284v., 291v., 296v.299, 410-413v AINSB, Fundo da irmandade de Nossa Senhora-a-Branca, Estatutos da confraria de Nossa Senhora das Neves, 1723, fls. 21-23v.; Estatutos da irmandade de Nossa Senhora das Neves, 1773, fls. 20v., 44; Estatutos da confraria de Nossa Senhora das Neves, 1788, fls. 26-28v.; AISVTE, Fundo da irmandade de São Vicente, Livro de estatutos reformados da irmandade de São Vicente, 1723, fls. 32-33, 49-51; Livro de estatutos reformados da irmandade de São Vicente, 1768, fls. 64-67.

${ }^{39}$ AINSB, Fundo da irmandade de Nossa Senhora-a-Branca, Estatutos da irmandade de Nossa Senhora-a-Branca, 1788, fls. 26-28v.

40 AISC, Fundo da irmandade de Santa Cruz, Livro de estatutos da irmandade de Santa Cruz, 1702, 1762, 1773, fl. 298v. Na Misericórdia de Guimarães, em 1740, os moços da sacristia recebiam três mil réis, vestuário e sapatos, mas apenas seis alqueires de pão (Costa, 1999, p. 224).
} 
Como vemos, certas irmandades aceitavam para as suas tarefas o concurso de moços com menos de 14 anos, que consideravam seus assalariados. Ora, é de salientar que, por vezes, estas confrarias tomavam o encargo de acompanhar os seus serventes à sepultura e de lhes mandar celebrar missas pelas suas almas, prestando-lhes deste modo assistência material e espiritual na hora da morte. ${ }^{41}$

A mortalidade infantil era, pois, um facto presente no devir das comunidades ocidentais de então. Vimos como a salvação das crianças batizadas até aos sete anos de idade estava garantida pela Igreja. Não necessitavam por isso de sufrágios para alcançar o Paraíso. E aquelas que tinham mais de sete anos? Como não faziam testamento, cabia aos pais providenciar-lhes a celebração de missas para assegurar a sua passagem segura para o Além, para lá da assistência espiritual mínima determinada pelas constituições do arcebispado bracarense, depois da morte. $4^{2}$ Não encontramos, no entanto, registo documental desses prováveis pedidos de celebração de missas por alma das crianças.

Contudo, seria possível que os bracarenses adultos, ao fazerem o seu testamento, se lembrassem de pedir a celebração de sufrágios por alma dos seus familiares defuntos, em especial dos seus filhos? O quadro seguinte, baseado na análise de 250 testamentos bracarenses setecentistas, mostra-nos quais os parentes que os testadores desejavam igualmente sufragar, quer nas missas celebradas durante o velório dos testadores, quer após o seu enterro:

\footnotetext{
${ }^{41}$ A Misericórdia de Setúbal tinha a seu serviço dois moços jovens de capela, com a função de ajudar os capelães na celebração das missas. A instituição alimentava-os, vestia-os e calçava-os. Sobre a Misericórdia de Setúbal consulte-se Abreu (1990, p. 113-114).

${ }^{42}$ As Constituições Sinodais de 1538 e as de 1697 previam a todos os defuntos, um ofício de enterro e uma missa de corpo presente. Constituições Synodais (1538, fls. XLIII, XLVI); Constituições Synodais (1697, p. 445).
} 
Quadro 1: Intenções familiares das missas de corpo presente e posteriores

\begin{tabular}{|c|c|c|c|c|c|c|c|c|c|c|c|}
\hline \multirow{2}{*}{$\begin{array}{l}\text { Intenções } \\
\text { familiares }\end{array}$} & \multicolumn{2}{|c|}{$1701-1720$} & \multicolumn{2}{|c|}{$1721-1740$} & \multicolumn{2}{|c|}{$1741-1760$} & \multicolumn{2}{|c|}{$1761-1780$} & \multicolumn{2}{|c|}{$1781-1800$} & \multirow[t]{2}{*}{ Total } \\
\hline & $\mathrm{M}$ & $\mathrm{F}$ & $\mathrm{M}$ & $\mathrm{F}$ & $\mathrm{M}$ & $\mathrm{F}$ & $\mathrm{M}$ & $\mathrm{F}$ & $\mathrm{M}$ & $\mathrm{F}$ & \\
\hline Pais & 2 & 2 & 1 & 9 & 8 & 8 & 8 & 7 & 7 & 9 & 61 \\
\hline Irmãos & 1 & 1 & & 6 & 2 & 2 & 2 & 4 & 1 & 6 & 25 \\
\hline Conjugues & 3 & & 1 & 2 & & 4 & 2 & 4 & 4 & 2 & 22 \\
\hline Filhos & 1 & & & 1 & 1 & 2 & 2 & 2 & 3 & 1 & 13 \\
\hline Tios & & 1 & 2 & 2 & & & 2 & 2 & 1 & 1 & 11 \\
\hline Avós & & & & 1 & & 1 & 2 & 2 & 2 & & 8 \\
\hline Sogros & & & & & 1 & & & 1 & 3 & 1 & 6 \\
\hline Cunhados & & & & & & 1 & 1 & 1 & & 1 & 4 \\
\hline Sobrinhos & & & & 1 & & 1 & & & & & 2 \\
\hline Primos & & & & & & & 1 & & & & 1 \\
\hline Madrinha & & & & & & & & & & 1 & 1 \\
\hline $\begin{array}{l}\text { Netas, quando } \\
\text { falecerem }\end{array}$ & & & & & & & & & & 1 & 1 \\
\hline $\begin{array}{l}\text { Outros } \\
\text { parentes }\end{array}$ & & & & & & & & & 1 & & 1 \\
\hline
\end{tabular}

Fonte: ADB, Testamentos do Fundo de Provedoria43; AISB, Livro de testamentos da freguesia da Sé, 1738-1785, fls. 10-10v., 12-13, 19-19v., 26v.-27v., 32-33, 35-36, 40v.-41, 50v.-51, 67v.-68, 74-75, 8585v., 89-89v., 111v.-112, 129-130., 134v.-135, 135, 147-148, 160-161, 165v.-166v., 175-176, 189, 197v.198; Livro de testamentos da freguesia da Sé, 1785-1814, fls. 5-5v., 37v.-38, 49v.-50, 57v.-58.

Como podemos constatar, pela análise dos dados aqui apresentados, os principais familiares por quem os testadores pediam missas, eram os seus pais em primeiro lugar, em seguida os seus irmãos e o conjugue, e só depois destes é que surgiam os filhos. $44 \mathrm{~A}$ análise deve ser efetuada com algum cuidado, pois um número ínfimo de testadores solicitou missas pelos familiares, quer de corpo

\footnotetext{
${ }^{43}$ Arquivo Distrital de Braga, doravante ADB, Testamentos do Fundo de Provedoria, Cotas 17, 18, 20, 22, 26, 27, 28, 29, 31, 33, 37, 38, $39,42,45,46,47,49,50,52,54,55,56,57,59,60,61,63,64,67,68,69,72,73,74,78,80,82,83,85,86,88,89,91,93,94,95,98$, $100,101,102,104,111,112,113,114,116,117,118,119,121,125,128,131,137,143,148,150,151,152,153,154,155,157,161$, $162,163,164,165,169,170,171,172,173,175,176,177,179,188,193,196,199,201,202,206,209,212,214,218,221,225,227$, $233,234,253,255,256,257,262,264,269,271,282,283,287,288,292,293,298,301,303,305,308,310,315,316,319,326,327$, $328,329,335,347,350,371,386,387,392,395,399,404,408,409,410,412,417,421,422,423,425,426,427,428,430,432,434$ $435,442,443,444,448,454,455,458,462,467,468,470,472,495,501,519,524,540,549,551,552,569,583,593,604,608,637$, $1717,1718,1721,1723,1726,1727,1728,1731,1732,1733,1734,1801,2987,3012,3018,3432,3797,4293,4294,4297,4298,4301$, 4302, 4303, 4306, 4308, 4310, 7153, 7229, 8057, 8058, 8059, 8064, 8065, 8067, 8068, 8070, 8077, 8078.

${ }^{44}$ Em Múrcia, na Época Moderna, pais, avós e demais parentes eram recordados nas missas de sufrágios pedidas pelos testadores. Confira-se a este respeito Alemán Illán (1987-1988, p. 73).
} 
presente, quer a título posterior o que inflaciona ligeiramente os registos apresentados.

O quadro aqui apresentado demonstra que não só o número de testadores que solicitou missas pelos seus familiares foi aumentando ao longo do século como, progressivamente, foram incluindo nestas intenções sufrágicas parentes num âmbito familiar mais alargado. Tendo começado por referir apenas os parentes mais próximos, como os pais, os irmãos e o cônjugue, certos testadores, à medida que avançava o século XVIII, foram progressivamente incluindo outros familiares nas intenções das eucaristias, como os filhos 45 .

Todavia, parece claro que o número de testadores que solicitavam esses sufrágios pelas almas de seus filhos era uma minoria. Uma outra dificuldade é a de não sabermos, aliás, as idades desses filhos defuntos, pelo que nem podemos afirmar com segurança que todos se tratassem de menores de 14 anos. Como já referimos, as crianças baptizadas, falecidas até aos sete anos de idade, tinham a salvação garantida, sendo desnecessária a celebração de sufrágios, o que também justifica um menor número de solicitações de missas com aquele intuito por parte dos testadores. Seriam estes sufrágios solicitados por alma de indivíduos com idade entre sete e catorze anos? É uma hipótese verosímil que queremos levantar. Não quisemos, assim, deixar de apresentar estes dados que referem uma certa preocupação com as almas dos seus descendentes falecidos, por parte de alguns indivíduos, fossem esses descendentes crianças ou não. Por isso esta é uma dimensão de análise que se mantém em aberto.

\section{Conclusão}

Aqui chegados, o que podemos afirmar sobre a vivência da morte e da salvação da alma, no que às crianças bracarenses setecentistas dizia respeito? O estudo arquivístico confraternal demonstrou indicadores claros de uma

\footnotetext{
45 Também Margarida Durães constatou a inclusão testamentária de missas de sufrágio pelas almas dos mais variados familiares dos testadores. Estes sufrágios, além de contribuírem para a salvação dos referidos parentes, reforçavam o laço de parentesco entre vivos e defuntos. Leia-se, sobre este assunto, Durães (2001, p. 330-331).
} 
diferenciação progressiva relativamente ao grupo etário infantil. As irmandades foram, ao longo da centúria, concedendo vantagens de preçário no acompanhamento e sepultamento dos filhos dos membros das suas fileiras, bem como de outros familiares. Se neste caso tal diferenciação não era especificamente dirigida às crianças, verificamos igualmente que certas confrarias possuidoras de um templo distinguiam favoravelmente o sepultamento dos menores, determinando preços inferiores em comparação com os adultos. Algumas destas instituições chegaram mesmo a constatar a pertinência de possuírem um caixão ou esquife próprio para o transporte dos menores.

A este aspeto adicionamos o facto que certas irmandades facultarem objectos simbólicos de adorno para aformosearem os seus restos mortais, durante o período de velório nas igrejas de que eram proprietárias. Parece-nos assim que a criança, paulatinamente, adquiria um espaço próprio dentro da temática abrangente da morte na Braga setecentista. Valorizava-se, sobretudo, a associação da imagem de uma alma pura que rapidamente gozaria da glória do paraíso. Efetivamente, num documento confraternal da época, as crianças defuntas eram designadas como "os anjinhos", ${ }^{46}$ sendo assim comparados a estes seres celestiais.

Uma dificuldade que se nos apresentou, foi a de nem sempre as referências das idades serem designadas de forma clara ou unívoca, podendo tratar-se de crianças até sete, 10 ou mesmo 14 anos, o que parece indicar uma certa ambiguidade no que respeita à delimitação do conceito de criança na Idade Moderna. Esta dificuldade foi também sentida na análise nos pedidos de missas por alma dos filhos, efetuada por uma minoria de testadores, pois não sabemos a idade daqueles à data de seu falecimento. Em conclusão, não podemos negar que se trataram ainda de análises longe de estarem concluídas e que certamente existe um grande caminho a desbravar relativamente ao papel da criança na vivência da morte da Época Moderna.

\footnotetext{
${ }^{46}$ AISV, Fundo da Congregação do Senhor das Necessidades, Livro de termos de mesa da Congregação do Senhor das Necessidades, 1768-1824/1849, fl. $118 \mathrm{v}$.
} 


\section{REFERÊNCIAS}

ABREU, J. P. Em Braga de 1790 a 1805: D. Frei Caetano Brandão: o reformador contestado. Braga: Universidade Católica Portuguesa; Faculdade de Teologia de Braga: Cabido Metropolitano e Primacial de Braga, 1997.

ABREU, L. A Santa Casa da Misericórdia de Setúbal de 1500 a 1755: aspectos de sociabilidade e poder. Setúbal: Santa Casa da Misericórdia de Setúbal, 1990.

ALEMÁN ILLÁN, A. La muerte en la sociedad murciana a finales del Antiguo Régimen: un estúdio cuantitativo de testamentos. Contrastes. Revista de História Moderna, Múrcia, v. III-IV, p. 71-90, 1987-1988.

ALVARENGA, M. J. C. Braga Triunfante. Coimbra: No Real Colégio das Artes da Companhia de Jesus, 1742.

AMORIM, M. N. Guimarães 1580-1819. Estudo Demográfico. Lisboa: Instituto Nacional de Investigação Científica, 1987.

APONTAMENTOS POR ONDE SE REGE ESTA CONGREGAÇÃO DO SENHOR DAS NECESSIDADES. Portugal: Braga, 1758-1780. Não paginado.

ARQUIVO DISTRITAL DE BRAGA. Testamentos do Fundo de Provedoria. Cotas. Portugal: Braga, [197-].

BARBOSA, M. H. V. Crises de mortalidade em Portugal desde meados do século XVI até ao início do século XX. Guimarães: Núcleo de Estudos de População e Sociedade do Instituto de Ciências Sociais da Universidade do Minho, 2001.

BLUTEAU. R. Vocabulário portuguez e latino. Tomo II. Coimbra: No Colégio das Artes da Companhia de Jesus, 1712.

BLUTEAU. R. Vocabulário portuguez e latino. Tomo VI. Coimbra: No Colégio das Artes da Companhia de Jesus, 1712.

BLUTEAU. R. Vocabulário portuguez e latino. Tomo VIII. Coimbra: No Colégio das Artes da Companhia de Jesus, 1712.

CAPELA, J. V. Fidalgos, nobres e letrados no governo bracarense. A administração económica e financeira da Câmara no apogeu e crise do Antigo Regime. Braga: Edição do Mestrado de História das Instituições e Cultura Moderna e Contemporânea, 1999.

CAPELA, J. V.; FERREIRA, A. C. Braga triunfante (Braga nas Memórias

Paroquiais de 1758). Braga: Universidade do Minho, 2002. 
CONSTITUIÇÕES SYNODAIS DO ARCEBISPADO DE BRAGA ORDENADAS NO ANNO DE 1639 PELO ILLUSTRÍSSIMO SENHOR ARCEBISPO D. SEBASTIÃO DE MATOS NORONHA E MANDADAS IMPRIMIR A PRIMEIRA VEZ PELO ILLUSTRÍSSIMO SENHOR D. JOÃO DE SOUSA. Lisboa: Oficina de Miguel Fernandes, 1697.

CONSTITUIÇÕES SYNODAIS DO ARCEBISPADO DE BRAGA. Lisboa: na oficina de Germão Galharde, 1538.

COSTA, A. F. S. A Santa Casa da Misericórdia de Guimarães 1650-180o (cardade e assistência no meio vimaranense dos séculos XVII e XVIII). Guimarães: Santa Casa da Misericórdia de Guimarães, 1999.

COSTA, J. A.; MELO, A. S. Dicionário da Língua Portuguesa. Porto: Porto Editora, 1994 .

COSTA, L. A igreja de São Victor. Elementos para a história deste templo. Braga: Edição da paróquia de São Victor, 1979.

DURÃES, M. Porque a morte é certa e a hora incerta... Alguns aspectos dos preparativos da morte e da salvação eterna entre os camponeses bracarenses (séculos XVIII-XIX).

Sociedade e Cultura 2 - Cadernos do Noroeste, Série Sociologia, Braga, v. 13, N. 2, p. 175-218, 2001.

ESTATUTOS DA CONFRARIA DA SENHORA DAS NEVES. Portugal: Braga, 1788.

ESTATUTOS DA CONFRARIA DE NOSSA SENHORA DAS NEVES. Portugal: Braga, 1723.

ESTATUTOS DA CONFRARIA DE NOSSA SENHORA DAS NEVES. Portugal: Braga, 1788.

ESTATUTOS DA IRMANDADE DE NOSSA SENHORA DAS NEVES SITA NA CAPELA DA SENHORA-A-BRANCA. Portugal: Braga, 1768/1773.

ESTATUTOS DA IRMANDADE DE NOSSA SENHORA DAS NEVES. Portugal: Braga, 1773 .

ESTATUTOS DA IRMANDADE DE NOSSA SENHORA DO Ó. Portugal: Braga, 1701.

GARNOT, B. La Population Française aux XVI, XVII et XVIII siécles. Paris: Ophrys, 1995.

LIVRO DA RECEITA DA IRMANDADE DE SÃO CRISPIM E SÃO CRISPINIANO. Portugal: Braga, 1748-1789.

LIVRO DE ESTATUTOS DA CONFRARIA DAS ALMAS DE SÃO VÍTOR. Portugal: Braga, 1738.

LIVRO DE ESTATUTOS DA IRMANDADE DE SANTA CRUZ, BOM JESUS DOS SANTOS PASSOS E SANTA ANA. Portugal: Braga, 1788. 
LIVRO DE ESTATUTOS DA IRMANDADE DE SANTA CRUZ. Portugal: Braga, 1663. LIVRO DE ESTATUTOS DA IRMANDADE DE SANTA CRUZ. Portugal: Braga, 1664. LIVRO DE ESTATUTOS DA IRMANDADE DE SANTA CRUZ. Portugal: Braga, 1702. LIVRO DE ESTATUTOS DA IRMANDADE DE SANTA CRUZ. Portugal: Braga, 1762. LIVRO DE ESTATUTOS DA IRMANDADE DE SANTA CRUZ. Portugal: Braga, 1773. LIVRO DE ESTATUTOS DA IRMANDADE DE SÃO CRISPIM E SÃO CRISPINIANO. Portugal: Braga, 1702.

LIVRO DE ESTATUTOS DA IRMANDADE DE SÃO CRISPIM E SÃO CRISPINIANO. Portugal: Braga, 1723.

LIVRO DE ESTATUTOS DA IRMANDADE DE SÃO CRISPIM E SÃO CRISPINIANO. Portugal: Braga, 1731.

LIVRO DE ESTATUTOS DA IRMANDADE DO BOM JESUS DOS SANTOS PASSOS. Portugal: Braga, 1747.

LIVRO DE ESTATUTOS REFORMADOS DA IRMANDADE DE SÃO VICENTE. Portugal: Braga, 1723.

LIVRO DE ESTATUTOS REFORMADOS DA IRMANDADE DE SÃO VICENTE. Portugal: Braga, 1768.

LIVRO DE TERMOS DE JUNTA DA IRMANDADE DE SÃO VICENTE. Portugal: Braga, 1796-1806.

LIVRO DE TERMOS DE MESA DA CONFRARIA DAS ALMAS DE SÃO VÍTOR. Portugal: Braga, 1752-1776.

LIVRO DE TERMOS DE MESA DA CONGREGAÇÃO DO SENHOR DAS NECESSIDADES. Portugal: Braga. 1768-1824/1849.

LIVRO DE TERMOS DE MESA DA IRMANDADE DAS ALMAS DE SÃO VÍTOR. Portugal: Braga, 1776-1794.

LIVRO DE TERMOS DE MESA DA IRMANDADE DE SÃO VICENTE Portugal: Braga, 1781-1790.

LIVRO DE TERMOS DE MESA DA IRMANDADE DE SÃO VICENTE. Portugal: Braga, 1796.

LIVRO DE TERMOS DE MESA DA IRMANDADE DO BOM JESUS DOS PASSOS. Portugal: Braga, 1740-1772. 
LIVRO DE TESTAMENTOS DA FREGUESIA DA SÉ. Portugal: Braga, 1738-1785.

LIVRO DE TESTAMENTOS DA FREGUESIA DA SÉ. Portugal: Braga, 1785-1814.

LIVRO DO RECIBO DA IRMANDADE DE NOSSA SENHORA DO Ó. Portugal: Braga, 1676-1724.

LIVRO DO RECIBO DA IRMANDADE DE NOSSA SENHORA DO Ó. Portugal: Braga, 1724-1771.

LIVRO DO RECIBO DA IRMANDADE DE NOSSA SENHORA-A-BRANCA. Portugal: Braga, 1669-1738-1803.

LIVRO DO RECIBO DA IRMANDADE DE NOSSA SENHORA-A-BRANCA. Portugal: Braga, 1669-1738.

LIVRO DO RECIBO DOS EMOLUMENTOS E ESMOLAS DAS COVAGENS, PANO DA SEPULTURA, DEPÓSITOS, LIMPEZA DOS ORNATOS DAS MISSAS GERAIS, SINAIS, REPIQUES E ESMOLAS. Portugal: Braga, 1754-1779.

LIVRO DOS EMOLUMENTOS OU ESMOLAS QUE SE DERAM PELAS COVAGENS, PANO DE SEPULTURA, DEPÓSITOS E LIMPEZA DOS ORNATOS DAS MISSAS GERAIS, SINAIS, REPIQUES E ESMOLAS. Portugal: Braga, 1779-1826.

LIVRO DOS PEDITÓRIOS DOS MORDOMOS DA IRMANDADE DAS ALMAS DE SÃO VÍTOR. Portugal: Braga, 1738-1754.

LIVRO DOS RENDIMENTOS DA CASA E ANAIS, 1628-1708 E DE 1737 ATÉ SE INCORPORAR NA IRMANDADE DE SANTA CRUZ EM 1772, DA IRMANDADE DOS SANTOS PASSOS E SANTA ANA. Portugal: Braga, 1628-1772.

LIVRO DOS TERMOS DA IRMANDADE DE SÃO CRISPIM E SÃO CRISPINIANO. Portugal: Braga, 1790-1874.

MARIZ, C. D. V. A Santa Casa da Misericórdia de Fão: quatro séculos de história. Fão: Santa Casa da Misericórdia de Fão, 2000.

MARQUES, J. F. A palavra e o livro. In: AZEVEDO, C. M. História religiosa de Portugal. Lisboa: Círculo de Leitores, 2000. v. 2. p. 377-447.

MORAES, J. M. Viver em penitência: os irmãos terceiros franciscanos e as suas associações, Braga e São Paulo (1672-1822). Braga: Universidade do Minho, 2009.

SÁ, I. G. As crianças e as idades da vida. In: MATTOSO, J. História da vida privada em Portugal. A Idade Moderna. Lisboa: Círculo de leitores, 2011. p. 72-95.

SANTOS, C. M. F. Santiago de Romarigães, comunidade rural do alto Minho: sociedade e demografia (1640-1872). Braga: Universidade do Minho \& Câmara Municipal de Paredes de Coura, 1999. 
SENNA DE FREITAS, B.- J. Memórias de Braga. Braga: Imprensa Católica, 1890a. v. II.

SENNA DE FREITAS, B.- J. Memórias de Braga. Braga: Imprensa Católica, 189ob. v. III.

SENNA DE FREITAS, B.-J. Memórias de Braga. Braga: Imprensa Católica, 1890c. v. V.

SILVA, R. M. A. Casar com Deus: vivências religiosas e espirituais femininas na Braga Moderna. Braga: Universidade do Minho, 2011.

SOARES, F. N. A arquidiocese de Braga no século XVII. Sociedade e mentalidades pelas visitas pastorais (1550-1700). Braga: Universidade do Minho, Governo Civil de Braga, 1997.

SOARES, M. I. E a sombra se fez verbo. Quotidiano feminino setecentista por Braga. Braga: Associação Comercial de Braga, 2009.

VOVELLE, M. Les âmes du purgatoire ou le travaile du deuil. Paris: Gallimard, 1996. 